Revista Iberoamericana, Vol. LXXII, Núm. 214, Enero-Marzo 2006, 11-15

\title{
INTRODUCCIÓN: CAMBIO CULTURAL Y LECTURA DE PERIÓDICOS EN EL SIGLO XIX EN AMÉRICA LATINA
}

\author{
POR \\ JuAn Poblete \\ University of California, Santa Cruz
}

Este volumen, que nació hace ya varios años en un panel de la Latin American Studies Association, se concentra en los periódicos (revistas, publicaciones periódicas, etc.) y su cultura de lecturas y lectores en el siglo xIx. Lo hace desde una perspectiva que busca desarrollar el tema no tanto desde el punto de vista ideológico o del contenido mismo sino más bien desde el punto de vista de las prácticas materiales. Intenta elaborar una reflexión colectiva sobre el periódico como aparato cultural nuevo y crucial en las dinámicas discursivas del siglo xix: circulación, lectores y formas de lectura, tipos de discursos y formatos, autoconcepción y objetivos en relación a un público lector, comunidades discursivas, jerarquías culturales.

En este proceso el volumen intenta escapar de varios problemas de enfoque que afectan de muy diversas maneras los estudios decimonónicos latinoamericanos: el predominio de una perspectiva centrada en el libro, la anacrónica y exclusiva concentración y búsqueda de novelas nacionales que permitan al investigador "fundar" la literatura nacional en la acción patriótica de algún autor-padre, masculino y singular; la correspondiente ceguera hacia otras formas discursivas y la anulación de la participación activa de múltiples públicos lectores (masculinos y femeninos, elitarios y populares) y de autores hoy considerados menores.

El debate sobre la novela nacional supuso en la América Latina de la segunda mitad del siglo xix una generificación de sus términos. Por “generificación” entiendo un proceso por el cual las divisiones entre los géneros sexuales acaban operando como categorías culturales definidoras y articuladoras de otras esferas de la vida social. En el siglo xix, la novela nacional misma resultó ser una intermediación entre dos polos culturalmente construidos, lo masculino y lo femenino, que constituían la cultura nacional. La lectura de novelas, es decir, la lectura por placer, apareció en este contexto como femenina, mientras que la lectura de los textos clásicos, supuestamente más ardua y selecta, resultó masculinizada.

Esta división de capacidades correspondía a formas de percepción cultural que efectuaban dos operaciones fundamentales. Por un lado, marcaban genérica y socialmente la lectura según la naturaleza del material y del sujeto lector: había así lecturas populares y lecturas de élite, lecturas para hombres y lecturas de mujeres, legítimas o ilegítimas, productivas o improductivas. Ligaban por otro, y de manera más general, la producción 
cultural y más específicamente, la producción textual nacional a un nuevo espacio de circulación de discursos: el mercado. En éste, todo lo que antaño había parecido sólido, si no se desvanecía en el aire, recibía al menos el impacto transformador de una nueva economía discursiva y social que afectaba los tiempos lentos y más estables de la antigua organización aristocrática de las sociedades nacionales latinoamericanas. Es en relación a esta anterior cultura patricia que resulta posible hablar de una protomasmediatización relativa de la cultura escrita en la América Latina decimonónica.

La lectura de periódicos, las lecturas hechas en periódicos (folletines, poemas, alabanzas, homenajes, necrologías, artículos, etc.) y nuevas o recicladas formas de discursividad impresa vinieron a ocupar progresivamente un lugar intermedio que terminaría por mediar la distancia entre aquellas formas de lectura socialmente construidas como "masculinas" y "femeninas". Por una serie de factores -entre los que cabe mencionar su facilidad de acceso y de compra, la facilidad correlativa de su lectura, la relativa brevedad del tiempo necesario para dar cuenta de la entrega del día, etc.- el periódico, y con él el folletín, las cartas, los remitidos, los poemas que aquel incluía, sería una de las formas textuales que haría posible la transición entre lo que se concebía socialmente como una lectura de estudio, masculina y sometida a la racionalidad de la inversión económica; y la lectura de placer, femenina y gobernada por la economía libidinal. Junto al periódico y al diario, aparecieron o se refuncionalizaron otros vehículos de la palabra escrita, como la revista, el álbum y el almanaque; y otras formas discursivas, como la poesía, la crónica social, el comentario de modas o de teatro y música, los consejos culinarios o de etiqueta, etc. Todos ellos fueron otros tantos espacios de escritura y lectura en que se libró la lucha por legitimar una cultura de tendencias mesocráticas que incorporara de manera decisiva a las mujeres y a los artesanos.

Estas nuevas formas de lecturas mediadoras representaban la existencia de un renovado contrato cultural nacional que aceptaba la necesidad y la existencia de públicos también nuevos y, sobre todo, heterogéneos. Esto supuso no tanto largas batallas como innumerables escaramuzas discursivas en que las nuevas formas que los intereses y estilos de vida de los públicos emergentes exigían, fueron poco a poco ocupando un espacio en las páginas y en los universos de lectura e interpretación de lectores y lectoras.

Folletín, crónica, comentario de modas, crítica cultural, cartas, remitidos, avisos comerciales, noticias políticas o comerciales, es decir las formas textuales que constituyen el universo semántico de la revista y del periódico en el siglo xix serían, entonces, lugares de mediación cultural entre los ahora diversos públicos, variados géneros (sexuales y discursivos) y múltiples textos y tempi que constituían las diferentes culturas nacionales y urbanas.

Este volumen intenta en su origen, entonces, explorar el periódico como instrumento y espacio social con consecuencias culturales profundas en tiempos de -aunque esto sea desigual según los países- rápida protomasificación relativa de la cultura escrita y leída en el continente.

A partir de esta convocatoria, los autores de los artículos aquí incluidos han desarrollado una extraordinaria y multifacética investigación de las diferentes aristas de la problemática sugerida en diversas situaciones nacionales. Sus aportes pueden dividirse en al menos tres grupos. El más numeroso incluye a aquellos autores que se dedican al 
análisis detallado de una o más publicaciones específicas (Chris Conway, Laurence Coudart, Alejandro Gortázar, Álvaro Kaempfer, Alejandro Mejías-López, Adela Pineda Franco, Kirsten Silva-Gruesz y Araceli Tinajero). Junto a ellos hay otro grupo que se realiza una reflexión más abstracta sobre el periódico como fenómeno cultural decimonónico (Horacio Legrás, Celia del Palacio Montiel, Juan Poblete, Lee Skinner). En un último conjunto podríamos agrupar los textos de Beatriz González-Stephan, Aníbal González y Fernando Unzueta. Ellos marcan dos de los límites al nivel de formato que delinean el universo sociosemántico de las publicaciones periódicas en América Latina y del tipo de circulación protomasiva de discursos sociales que ellas representaron. Mientras Aníbal González y Fernando Unzueta estudian la relación entre novelas y periódicos, Beatriz González Stephan investiga la aparición de un nuevo fenómeno en la cultura nacional: las grandes exposiciones que pusieron a prueba los límites de la cultura letrada decimonónica.

En orden alfabético y, a menudo, en sus propias palabras, se listan resumidamente a continuación los enfoques de los artículos que integran el volumen.

Chris Conway ("Letras combatientes: una relectura de la Gaceta de Caracas, 18081822”) investiga el primer periódico venezolano, la Gaceta de Caracas, y propone que este primer periodismo funcionó por medio del concepto del compendio escriturario, un archivo de documentos locales e internacionales, privados y públicos, cuya función era centralizar las distintas corrientes de la vida pública colonial y republicana en un espacio simbólico compartido.

Laurence Coudart ("Función de la prensa en el México independiente: el correo de lectores de El Sol (1823-1832)”) analiza con gran detalle la sección de remitidos de los lectores en un periódico mexicano para entender cómo los problemas de la formación de la nación (centralización, alfabetización, representación política y cultural, etc.) se relacionan, al menos en parte, con las maneras de conceptualización y con la formación de un "público ilustrado" suficientemente amplio y unificado para "guiar al pueblo".

Aníbal González ("Periodismo y novela en Hispanoamérica: la ley del disimulo en Amalia de José Mármol y Temochic de Heriberto Frías”) analiza por la vía de nociones como disimulo y mimetismo algunas de las estrategias retóricas y narrativas que la novela tomó prestadas del periodismo decimonónico.

Beatriz González Stephan (“El ordenamiento de la cultura nacional: una vitrina para la exportación (la Exposición Venezolana de 1883)”) analiza de la mano de José Martí las exposiciones como nuevos fenómenos de la cultura de masas. Esto supone destacar algunos nudos soslayados por las élites letradas: la carga simbólica de la cultura material o el sentido social de las cosas; el peso cultural de la producción material y tecnológica; la constatación de un nuevo sujeto moderno multitudinario consumidor de cultura; la capacidad ilimitada de interpelación de las modalidades de las culturas visuales, y, en este sentido, el carácter restringido y disfuncional de la cultura letrada para llevar a cabo la modernización en América Latina.

Alejandro Gortázar (“La 'sociedad de color' en el papel: La Conservación y El Progresista, dos semanarios de los afro-uruguayos”) trabaja sobre la hipótesis de que el discurso de reconstrucción de la raza promovido por los semanarios La Conservación y El Progresista (publicaciones que evidencian la existencia de un público y una literatura producida y consumida por los afro-uruguayos a finales del siglo xIX) está basado en una 
ruptura radical con el pasado esclavista así como en los nuevos desafíos que los afrouruguayos debieron enfrentar en esa nueva etapa de consolidación del Estado-nación que comprendió, entre otras cosas, las demandas de igualdad real, la unión de la comunidad afro-uruguaya y la necesidad de su ilustración letrada.

Álvaro Kaempfer ("Periodismo, orden y cotidianeidad: Presentación de la Gaceta de Buenos Aires de Mariano Moreno (1810) y Prospecto de la Aurora de Chile (1812) de Camilo Henríquez") sostiene que desde circunstancias, momentos y lugares diferentes, la Gaceta y la Aurora atarían una escritura de emancipación, basada en el reclamo de soberanía de los cabildos hispanoamericanos, al disciplinamiento ideológico de un cuerpo político capaz de ejercerla. En ellos, la creación de un espacio público iba unida al desafío de crear un nuevo orden y asegurar su gobernabilidad mediante la puesta en circulación de una cotidianeidad noticiosa.

Horacio Legrás (“Leer para pasar de siglo”) intenta una revisión del problema de las publicaciones periódicas y sus públicos en el fin de siglo argentino. Para ello estudia primero el Anuario bibliográfico de Navarro Viola, luego, una novela de Antonio Argerich en la que persigue la representación literaria elitista de la lectura masiva popular y, finalmente, la famosa revista Caras y caretas como primera solución al "problema” de los públicos masivos.

Alejandro Mejías-Lopez (““CConocer y ser conocido’: identidad cultural, mercado y discursos globales en tres revistas latinoamericanas de entre siglos”) estudia la constitución de un paradigma discursivo latinoamericano en el período de entre siglos mediante el cual los intelectuales toman conciencia de la importancia de los discursos representacionales en un momento en el que las condiciones materiales, económicas, y culturales del siglo XIX están consolidando lo que en su momento se concibió como un nuevo orden mundial, esto es, lo que hoy podemos llamar una primera etapa de globalización. Se centra para ello en el ámbito de las publicaciones periódicas de carácter cultural y en particular en aquellas que fueron editadas y publicadas fuera de Latinoamérica, en los que eran percibidos como centros mismos de la modernidad, Nueva York y París.

Adela Pineda Franco ("Más allá del interior modernista: el rostro porfiriano de $L a$ Revista Moderna (1903-1911)”) explora la Revista Moderna (1898-1903), posteriormente Revista Moderna de México (1903-1911) en su capacidad de cohesión social y cultural, es decir, en su función hegemónica en la sociedad porfiriana al integrar a un público diversificado dentro de los límites marcados por el concepto de ciudadanía porfiriana.

Celia del Palacio Montiel ("Redes de información y circulación de impresos en México. La prensa de Guadalajara en las primeras décadas del siglo XIX”) analiza de qué manera circularon los periódicos de Guadalajara en los primeros años del siglo XIX y explica cómo algunos datos al respecto pueden rastrearse a través de la prensa misma.

Juan Poblete (“La revista, el periódico y sus lectores en el Chile decimonónico”) propone una suerte de fenomenología cultural de la revista y del periódico para entender tanto los objetos comunicacionales que ellos constituyen como la formación de sus públicos lectores en el siglo XIX y sus consecuencias culturales.

Kirsten Silva-Gruesz ("Hacia un mundo nuevo latino: los periódicos hispanos en Estados Unidos a fines del siglo XIX”) estudia periódicos en lengua hispana en los Estados Unidos para destacar los recursos que poseían las comunidades hispanoparlantes para 
llegar a la autoconciencia por medio no sólo de sus intercambios con la mayoría angloparlante, sino también de una red profunda de enlaces entre distantes comunidades de imprenta.

Lee Skinner ("El discurso religioso y los papeles de la mujer en el periodismo decimonónico hispanoamericano”) investiga algunos de los debates que tuvieron lugar en las páginas de la prensa sobre la necesidad de educar a la mujer, las ventajas y las desventajas de la emancipación femenina y la naturaleza innata de la mujer.

Araceli Tinajero (“El Siglo, La Aurora y la lectura en voz alta en Cuba, 1865-1868”) estudia la lectura en voz alta de periódicos de artesanos en Cuba hacia finales del siglo XIX pero, en particular entre 1865-1868. El trabajo busca comprender cómo y en qué forma la literatura leída en voz alta sirvió de instrumento cultural y didáctico para la clase trabajadora de fin de siglo.

Fernando Unzueta ("Soledad o el romance nacional como folletín: proyectos nacionales y relaciones intertextuales”) sugiere que leer literatura (y especialmente novelas sentimentales) en las páginas periódicas donde salen en su mayor parte, y hacerlo tomando en cuenta ese medio, con su multiplicidad y variedad de mensajes, aporta nuevas perspectivas sobre lo que se entiende en y sobre esos textos.

Finalmente quisiera agradecer, primero, la paciencia y profesionalismo de los colaboradores durante el largo proceso de gestación del volumen y, luego, el excelente trabajo editorial de Erika Braga, Patricia Sanders y Mabel Moraña. 